\title{
Public attitudes to science in South Africa
}

AUTHORS:

Vijay Reddy

Michael Gastrow ${ }^{1}$

Andrea Juan ${ }^{1}$

Benjamin Roberts ${ }^{2}$

\section{AFFILIATIONS:}

${ }^{1}$ Education \& Skills Development, Human Sciences Research Council, Durban, South Africa

${ }^{2}$ Democracy, Governance and Service Delivery, Human Sciences Research Council,

Durban, South Africa

\section{CORRESPONDENCE TO: Vijay Reddy}

EMAIL:

vreddy@hsrc.ac.za

\section{POSTAL ADDRESS:}

Education \& Skills Development, Human Sciences Research Council, Private Bag X07, Dalbridge 4014, South Africa

\section{DATES:}

Received: 28 Mar. 2012

Revised: 27 July 2012

Accepted: 10 Aug. 2012

\section{KEYWORDS:}

public relationship with science; South Africa; science governance; attitudes towards science; social attitudes survey

\section{HOW TO CITE:}

Reddy V, Gastrow M, Juan A, Roberts B. Public attitudes to science in South Africa. $S$ Afr J Sci. 2013;109(1/2), Art. \#1200, 8 pages. http://dx.doi. org/10.1590/sajs.2013/1200

(c) 2013. The Authors. Published under a Creative Commons Attribution Licence.
In a global environment characterised by the growing role of science and technology in our economic, social, and political lives, an international research agenda has arisen to measure and understand how science and technology are perceived and evaluated by the public. In 2010, the South African Social Attitudes Survey included 20 items to measure public attitudes towards science, knowledge about science, and sources of information about science. This household survey was administered to a representative, stratified, random sample of 3183 participants. The findings were analysed through a bivariate analysis, and here we report on South African attitudes towards science and technology, how these have changed between 1999 and 2010, and where South African science attitudes fit on the canvas of global science attitudes. The data reveal a complex and shifting relationship between attitudes of promise and reservation towards science in South Africa. In the international context, South Africa has a unique 'fingerprint' of public attitudes towards science. The strongest demographic variable impacting on attitude towards science was educational attainment, followed by age. Gender had no impact on science attitude. This broad overview also highlights some directions for further research to meet the growing academic and policy interest in the interface between the institutions of science and the public.

\section{Introduction}

Science and technology play a large and growing role in our economic, social and cultural lives. Measuring and understanding the structures and dynamics of this role has taken on an increasing significance. Globally, and in South Africa, there has been a sustained effort to measure the economic impact of advances in science and technology. Internationally there is also a history of scholarship that seeks to measure and understand, largely through survey instruments and the analysis of survey data, the way in which knowledge of and attitudes to science are structured in societies - how they vary across demographics, across different aspects of science, and particularly how the public responds to areas of scientific controversy such as nuclear energy, genetic modification, climate change and stem cell research. Because these data have been collected for several decades - at least in Europe and the USA - the literature also seeks to track changes in these knowledge and attitudinal structures over time, in order to understand the trajectories that shape the current and future role of science in culture and society.

This broad area of research conceives of and measures attitudes to science and technology as a social construct located within the public sphere. ${ }^{1}$ This research has employed the rubrics of 'the public understanding of science,' 'science and society', and 'science literacy', among others. This paper is positioned within a 'science and society' framework, with a focus on the attitudinal aspect of this relationship. This focus recognises that attitudes are contextually formed through complex interactions between the public and the institutions of science and technology. As such, in this paper, we offer a first step towards a better understanding of this relationship. Further analysis drawing on our recent data sources will add further dimensions to this understanding by looking at data describing science knowledge and science communication in South Africa and by performing more in-depth statistical analyses.

Numerous international surveys, most notably in the European Union through the Eurobarometer, in the USA through the National Science Foundation surveys, and in some developing countries like India, ${ }^{2}$ have measured the public's relationship with science. These surveys have focused on questions of science literacy, attitudes towards science and science communication. A considerable literature has developed to analyse these data, with the aim of gaining a greater understanding of what the public knows about science, how the public feels about science, and how the public learns about science..$^{1,3}$ These lessons have many applications for policymakers, firms and researchers, particularly as they negotiate future science policy., ${ }^{4,5}$

The South African Ministry of Science and Technology's Ten-Year Plann ${ }^{6}$ recognises the importance of supporting the public's understanding of and engagements with science and technology if South Africa is to become a more innovative society with a more democratic and participatory mode of science governance. A 2009 study for the South African Agency for Science and Technology Advancement reviewed research undertaken in South Africa. ${ }^{2}$ On this basis, a specialised module was developed for the 2010 South African Social Attitudes Survey (SASAS), conducted by the Human Sciences Research Council, which included 20 items to measure the attitude, knowledge and sources of information for science and technology among the South African public. This survey is the most recent nationally representative and internationally comparable survey to address some of these questions in South Africa.

In this analytical-descriptive paper, we use the data rendered by this survey to answer three key questions: (1) What are South African attitudes to science and technology? (2) How have these attitudes changed over time? and (3) Where do South African science and technology attitudes fit on the canvas of global science attitudes? Our primary objectives in this paper were to provide a broad overview of the South African public's attitudes towards science, to provide an empirical grounding for further discussion about the interactions between the public, society and science institutions, and to highlight directions for further research. 


\section{Theoretical approaches to the public's relationship with science} A constructive relationship between the public and science can support economic and social development; it allows the public to be informed about key issues where science and technology may offer solutions to development challenges, stimulates interest in science subjects and careers, encourages investment in $R \& D$, and increases public participation in science policy formulation and adoption. ${ }^{7}$ The assessment of the relationship between science and the public has been located in different theoretical paradigms that have evolved over time. A substantial body of research is related to this broad theoretical movement. ${ }^{1,4,8}$ Some studies are based on an experiential approach, ${ }^{9}$ which focuses on the nature of the experience of engaging with scientific learning. A more common approach, the 'deficit model', ${ }^{3}$ supposes that the public lack sufficient knowledge about science, and seeks to increase levels of scientific knowledge. Related debates include those on scientific citizenship and the democratic governance of science, ${ }^{10,11}$ the role of participation in science, ${ }^{12}$ and cultural aspects of science knowledge and attitudes. ${ }^{13}$

The most widely used framework used to assess the relationship between the public and science is termed the 'public understanding of science' (PUS). This approach holds that more effective communication of science and technology information - with a focus on shaping public attitudes, as well as public scientific literacy - should result in more constructive attitudes and increased interest. ${ }^{1,3,4}$ Major international surveys, such as the Eurobarometer and the US National Science Foundation surveys, use normative measures based on the PUS model. ${ }^{14}$

The assumption of a causal relationship between scientific literacy and positive attitudes towards science has been questioned. Allum et al. $^{3}$, in a meta-analysis of 193 PUS studies, found a weak positive correlation between scientific literacy and attitudes, but this was not sufficient to indicate a causal relationship. Also, the relationship between general attitudes to science and attitudes to specific scientific issues is complex. Unpacking the determinants of such a divergence requires an analysis that seeks to examine attitudes towards science as social constructs, which was not possible under the limitations of the PUS model. During the 1990s, the 'science in society' paradigm emerged out of these criticisms. This model held that the relationship between science and the public is not based only on literacy or attitudes, but also on the public's social, cultural and political environments. ${ }^{1}$ The 'science in society' model examines options for institutional change which will see a greater involvement of the public in the policy formulation process. Science communicators (such as journalists or public information officers) are vital in the process of the science community and the public working together with the aim of building both scientific knowledge and constructive attitudes towards science. ${ }^{14}$

\section{Measurement of science attitudes}

Numerous studies on the public's relationship with science have been conducted internationally, including in the USA, Europe, Canada, Russia, China, Japan, Korea, India and Malaysia. ${ }^{2}$ There is considerable overlap in the items used in these studies. ${ }^{15}$ For example, the US, European and Indian surveys all used the 'promise-reservation index' - a set of seven attitudinal questions. The National Science Foundation in the USA releases 'science and engineering indicators' every 2 years. Surveys have been conducted on 'public attitudes towards and understanding of S\&T' periodically since 1979 . The most recent set of indicators was published in 2012 using 2010 data. For greater comparability of items, we used the 2008 data. ${ }^{16}$ The survey was administered to approximately 1600 respondents and included questions on both attitudes towards

Table 1: $\quad$ South African surveys that have included items related to the public's relationship with science

\begin{tabular}{|c|c|c|c|c|}
\hline $\begin{array}{l}\text { Coordinating institution/ } \\
\text { investigator }\end{array}$ & Survey & Year of data collection & Data collection method & Sample size \\
\hline World Value Survey² & World Values Survey (Wave 5) & 2007 & $\begin{array}{l}\text { Face to face interviews, } \\
\text { household survey }\end{array}$ & 2988 \\
\hline \multirow{4}{*}{ Pouris } & $\begin{array}{l}\text { Understanding and Appreciation of } \\
\text { Science Among the Public in South } \\
\text { Africa }^{19}\end{array}$ & 1991 & $\begin{array}{l}\text { Face to face interviews } \\
\text { in six suburbs }\end{array}$ & 1300 \\
\hline & $\begin{array}{l}\text { Understanding and Appreciation } \\
\text { of Science Among South African } \\
\text { Teenagers }{ }^{20}\end{array}$ & 1993 & $\begin{array}{l}\text { Face to face interviews } \\
\text { in suburbs }\end{array}$ & 800 \\
\hline & $\begin{array}{l}\text { Interests, Public Attitudes and } \\
\text { Sources of Scientific Information in } \\
\text { South Africa }{ }^{21}\end{array}$ & 2001 & $\begin{array}{l}\text { Face to face interviews } \\
\text { in metropolitan areas }\end{array}$ & 1000 households \\
\hline & $\begin{array}{l}\text { Assessing Public Support for } \\
\text { Biotechnology in South Africa22 }\end{array}$ & 2004 & $\begin{array}{l}\text { Face to face interviews } \\
\text { in consumer survey }\end{array}$ & 1000 households \\
\hline Laugksch & $\begin{array}{l}\text { Test for Scientific Literacy and its } \\
\text { Application in Assessing Scientific } \\
\text { Literacy of Matriculants Entering } \\
\text { Universities and Technikons }\end{array}$ & 1994 & $\begin{array}{l}\text { Questionnaires to } \\
\text { first-year students in } \\
\text { Western Cape tertiary } \\
\text { institutions }\end{array}$ & 4227 \\
\hline \multirow{6}{*}{$\begin{array}{l}\text { Human Sciences Research } \\
\text { Council }^{24}\end{array}$} & Omnibus Survey & 1995 & Face to face interviews & 2200 \\
\hline & $\begin{array}{l}\text { Evaluation of Public Opinion } \\
\text { Programme }\end{array}$ & 1999 & $\begin{array}{l}\text { Face to face interviews, } \\
\text { household survey }\end{array}$ & 2207 \\
\hline & SASAS: Biotechnology & 2004 & $\begin{array}{l}\text { Face to face interviews, } \\
\text { household survey }\end{array}$ & 5684 \\
\hline & SASAS: Climate Change & 2007 & $\begin{array}{l}\text { Face to face interviews, } \\
\text { household survey }\end{array}$ & 3164 \\
\hline & $\begin{array}{l}\text { SASAS: Indigenous Knowledge } \\
\text { Systems }\end{array}$ & 2009 & $\begin{array}{l}\text { Face to face interviews, } \\
\text { household survey }\end{array}$ & 3305 \\
\hline & $\begin{array}{l}\text { SASAS: Nuclear Technology and } \\
\text { Energy }\end{array}$ & 2011 & $\begin{array}{l}\text { Face to face interviews, } \\
\text { household survey }\end{array}$ & 3057 \\
\hline
\end{tabular}


and knowledge about science and technology. The Eurobarometer survey occasionally includes modules on the public relationship with science. The most recent of these was conducted in 2010 with a sample of 31238 respondents across 32 countries. ${ }^{17}$ India has pioneered the measurement of the public's relationship with science in the developing country context. In 2004, India's National Council of Applied Economic Research commissioned a national study, with a sample of over 30000 individuals. ${ }^{18}$

In South Africa, the Foundation for Education, Science and Technology has undertaken a few dedicated surveys to measure the public's relationship with science. Studies have also been undertaken by Pouris ${ }^{19}$, but none were nationally representative of the South African adult population. The Human Sciences Research Council has also occasionally included sets of science attitudinal items in its national surveys and has undertaken surveys on specialised topics of biotechnology and climate change. ${ }^{2}$ Table 1 lists the surveys, undertaken in South Africa, which include items related to the public's relationship with science.

\section{Methodology}

Our primary data set was drawn from the 2010 wave of the SASAS, which has been conducted annually by the Human Sciences Research Council since 2003. ${ }^{24}$ The sample responding to the public's attitudes to science module consisted of 3183 participants over the age of 16 . The weighted profile of the sample was $48 \%$ male and $52 \%$ female; $77 \%$ African, $9 \%$ Coloured, $3 \%$ Indian and $11 \%$ White. Two-thirds of the participants lived in urban areas (55\% in formal and $11 \%$ in informal dwellings) and one-third in rural areas $(28 \%$ in rural or traditional authority and $6 \%$ in farmworker households). The weighted educational and unemployment levels of the sample increased from 1999 to 2012 (Table 2).

Table 2: Age profile, educational level and employment status of the South African Social Attitudes Survey sample

\begin{tabular}{l|l|l}
\hline \hline & $\mathbf{1 9 9 9}(\mathbf{\%})$ & $\mathbf{2 0 1 0} \mathbf{( \% )}$ \\
\hline \hline Age range & & \\
\hline $16-19$ & 6 & 10 \\
\hline $20-29$ & 26 & 32 \\
\hline $30-39$ & 26 & 20 \\
\hline $40-49$ & 17 & 15 \\
\hline $50-59$ & 12 & 11 \\
\hline$>60$ & 14 & 11 \\
\hline Educational level & & \\
\hline No schooling & 8 & 4 \\
\hline Primary & 24 & 14 \\
\hline Grades 8 to 11 & 37 & 36 \\
\hline Matric or equivalent & 21 & 34 \\
\hline Tertiary & 11 & 11 \\
\hline Employment status & & \\
\hline Employed: full time & 37 & 26 \\
\hline Employed: part time or casual & 7 & 7 \\
\hline Unemployed: looking for work & 25 & 32 \\
\hline Unemployed: not looking for work & 7 & 9 \\
\hline Pensioner, sick or disabled & 15 & 12 \\
\hline Student & 10 & 12 \\
\hline & & \\
\hline
\end{tabular}

In this sample, three explicit stratification variables were used: province, geography type and majority population group. Within each stratum, the allocated number of participants was drawn using proportional-to-size probability sampling. The SASAS items were validated and translated into appropriate languages. Within the broader survey instrument, which included social, cultural, economic, demographic and geographical data, a module on the public's relationship with science contained 20 closedended questions developed from a literature review and exploratory scoping research. ${ }^{2}$ The public's relationship with science survey module consisted of three sections: attitudes towards science (the promisereservation index, with one modification), scientific knowledge, and sources of scientific information.

The promise-reservation index has been used globally in studies of public attitudes towards science. ${ }^{2,16}$ This index includes four questions which measure attitudes about the promise (or potential benefits) of science, and three which measure reservations about science such as concerns, fears and risks (see Appendix 1). This set of seven attitudinal questions is answered with a five-point rating scale, ranging from strongly agree to strongly disagree. Each of these questions is an indicator of attitudes towards a particular aspect of science. It is then possible to construct an index of promise (using the 'promise' questions) and an index of reservation (using the 'reservation' questions). The 'promise-reservation index' reverses the answers to the 'promise' and 'reservation' questions so that the highest possible score represents strong agreement while the lowest possible score represents strong disagreement. The promise and reservation indices are calculated by aggregating all responses of 'strongly agree' or 'agree' and dividing by the number of items constituting the respective index. The average promise score is then divided by the average reservation score to provide a single promisereservation ratio of attitudes towards science - in which a higher score indicates a generally more positive attitude.

The Cronbach alpha coefficient for the scientific promise index was 0.68 and for the reservation index was 0.40 . The alpha coefficient for the reservation index is low and of concern. The implication is that the respondents did not consistently respond to the items. In this initial study, we adhered to international norms for measuring scientific promise and reservation and these reliability tests speak to the need for future analytical and methodological testing. The findings presented here are drawn from the promise-reservation items of the survey.

The SASAS scientific attitudinal items are comparable to our international data sources, which include items from the US National Science Foundation surveys, ${ }^{16}$ the Eurobarometer ${ }^{17}$ and a national survey in India. ${ }^{18}$ Because of the nature of the data available from the other international reports, direct comparison using age categories was not possible. For illustrative purposes, the age categories 'youth', 'adult' and 'senior' are used. For the Indian data, the category 'youth' applies to the age group 10-30 years, 'adult' refers to 31-45 year olds and 'senior' refers to those older than 45 years. For the Eurobarometer, South African and US data, 'youth' applies to those under 24 years, 'adult' refers to the 25-54 year-old group and 'senior' refers to those older than 55 years. Although 2008 data was primarily used for the USA, data from the item 'The benefits of science are greater than any harmful effects' was taken from the 2010 data in the interests of maximising comparability.

To allow for trend analysis of our South African data, data from the 1999 Evaluation of Public Opinion (EPOP) survey were used. This predecessor of the SASAS was administered amongst a nationally representative sample of 2207, and included the promise-reservation set of items, which makes it possible to compare South African attitudes towards science in 1999 and 2010 on representative cross-sectional data.

Our data was analysed using SPSS 19. Data analyses included frequencies to describe single variables, cross-tabulation to describe the associations between variables, and parametric tests of significance (at the $95 \%$ level of confidence) to determine whether changes between sub-groups were statistically significant. In this paper we have limited our analysis to the bivariate level to establish patterns and trends with a view to conducting more focused analyses at a later stage. Many avenues of further investigation are possible using the rich data set provided by the 2010 SASAS, including more detailed explorations of demographic variables, science knowledge items and science communication items. Increased complexity of the quantitative analysis, including multivariate regression analyses, can also be informed by the findings of this paper. 


\section{Findings}

Differentiation by these demographic variables renders a number of stratified 'publics' within the broader South African public. Our analysis of public attitudes towards science was structured by these variables, with the aim of understanding how these different 'publics' feel about science.

\section{Changes in South African attitudes from 1999 to 2010}

Figure 1 illustrates aggregate results from the SASAS 2010 and EPOP 1999 surveys. The first three questions are indicators of reservation and the last six questions are indicators of promise. Six items are common to both SASAS 2010 and EPOP 1999 and the other three appear in either the 2010 or 1999 surveys. Each question tests for attitudes towards a different aspect of science, including attitudes towards science as a career, the impact of science on the work environment, the motives of scientists, the balance between the risks and benefits of science, optimism about the impact of science on the future, the relevance of science to everyday life and personal well-being, the relationship between science and faith, and the impact of scientific and technological change.

The results reveal a dynamic mixture of positive and negative attitudes. Over $70 \%$ of participants responded positively to questions asking whether science and technology (1) makes their lives easier, healthier, and more comfortable, (2) makes work more interesting, and (3) creates more opportunities for the next generation. However, the majority of the public were concerned that science makes our way of life change too fast, and that we depend too much on science and not enough on faith. Just over half thought the benefits of science were greater than the harmful effects.
The changes between 1999 and 2010 reveal some interesting patterns (Figure 1). As a result of a general slight weakening of promise attitudes and strengthening of reservation ones, the overall promise-reservation ratio decreased from 1.4 to 1.2. The three 'promise' items for which there were both 1999 and 2010 data (Questions 4-6) showed a statistically significant drop of 1,1 , and 4 percentage points, respectively, indicating a slight decline in attitudes towards scientific promise that is reflected in a drop in the overall promise index from 73 in 1999 to 70 in 2010.

The change in response to the reservation items from 1999 to 2010 was also statistically significant. The first reservation item (Question 1) showed a small decline (5\%) from 1999 to 2010, indicating that people in 2010 were more likely to think that some science knowledge is important in everyday life. On the other hand, there were larger increases in the other two reservation items (Questions 2 and 3), which underpin an increase in the overall reservation index from 49 in 1999 to 56 in 2010. There was an increase of five percentage points for the statement 'Science makes our way of life change too fast', suggesting that coping with scientific and technological change has become increasingly difficult in South Africa. The capacity for technological change to cause harmful psychological effects, including increased stress levels, has been widely but disparately investigated, ${ }^{25,26}$ including in South Africa. ${ }^{27}$

The largest change between 1999 and 2010 was in the responses towards the statement 'We depend too much on science and not enough on faith'. In 1999, $42 \%$ of participants agreed with this. In 2010, $59 \%$ agreed - an increase of 17 index percentage points. In SASAS 2010, 83\% of the sample indicated that they had a religious affiliation. Paradoxically, this figure is $95 \%$ for 1999. It is interesting that this major change is in a cultural indicator rather than an indicator about the practical application of

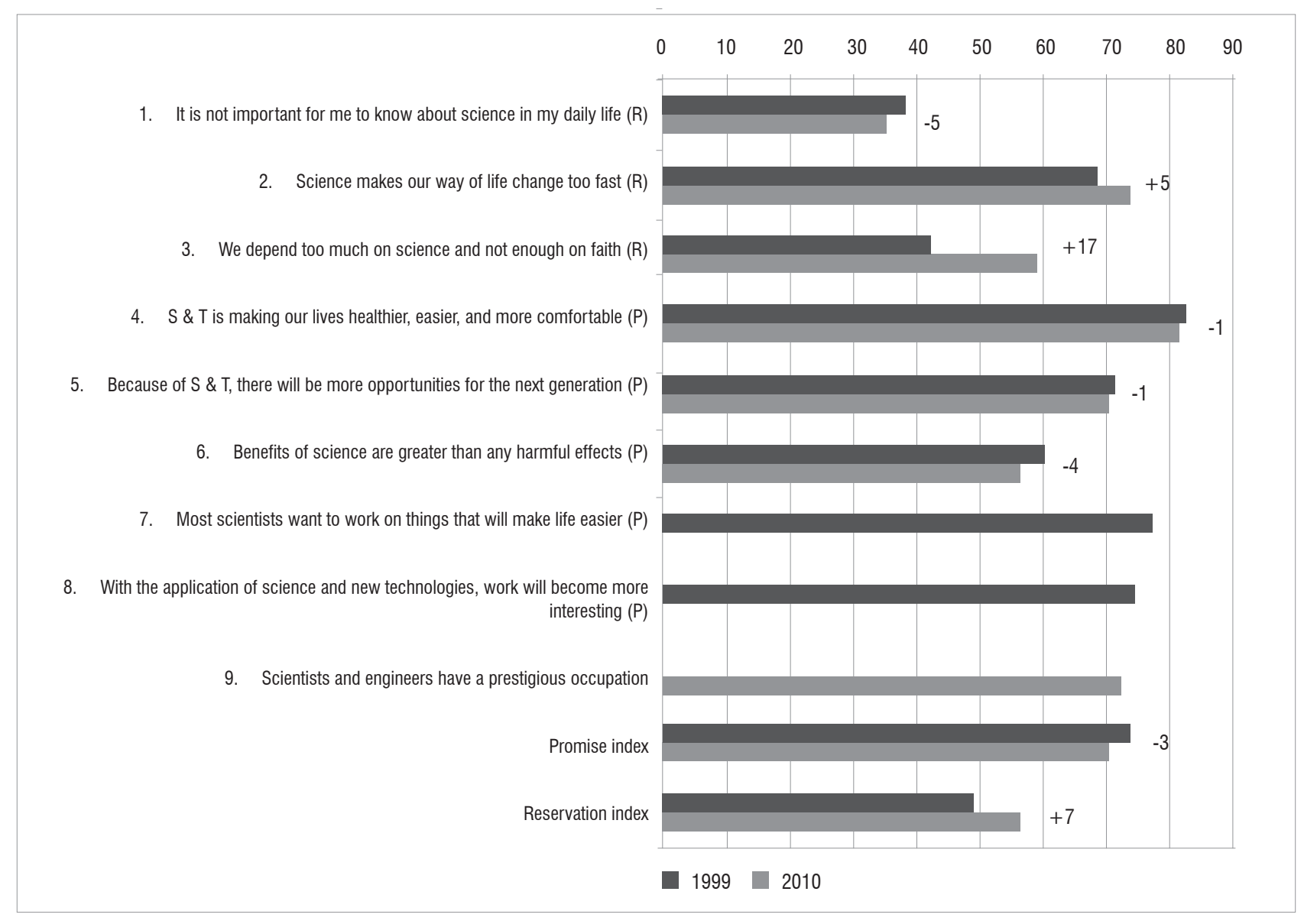

$R$, reservation item; $P$, promise item

Figure 1: Comparison of performance on promise-reservation items between 1999 and 2010. 
science; this fact highlights that understanding attitudes towards science requires an understanding of cultural context as well as economic application. The culturally conditioned tension between science and religion, often in the context of secularisation, has been a central concern of social theorists since the European Enlightenment ${ }^{28}$ because science and religion offer sometimes irreconcilable epistemologies, ontologies and moral values.

\section{Comparison of South African, European, Indian and US attitudes}

Figure 2 shows a comparison of South African attitudes with European (measured through the Eurobarometer), US (measured through the National Science Foundation survey) and Indian attitudes to science.

Internationally, the promise-reservation ratio appears to increase with levels of economic development; in 2010, the GDP per capita in the USA was $\$ 47184$, in the EU $\$ 31676$, in South Africa $\$ 10486$, and in India $\$ 3586 .{ }^{29}$ In India, the promise-reservation ratio was 0.8 , in South Africa 1.2 , in Europe 1.4 and in the USA 1.7. However, there was considerable variation at the disaggregated level, where every country had a unique pattern of responses. South African attitudes were closer to European attitudes on three items ('It is not important for me to know about science in my daily life', 'Because of S\&T, there will be more opportunities for the next generation' and 'Benefits of science are greater than any harmful effects'); closer to Indian attitudes on two items ('Science makes our way of life change too fast' and 'S\&T is making our lives healthier, easier, and more comfortable') and similar to US attitudes for the item 'We depend too much on science and not enough on faith'.

Internationally, some items reveal a greater range of responses among countries than others. The smallest range is for the statement 'Science and technology make our lives healthier, easier, and more comfortable'. Here the difference between the highest response (USA $=90)$ and the lowest response (India $=77$ ) is $13 \%$, indicating a fair degree of similarity in public opinion. The greatest divergence is for the items 'Because of science and technology there will be more opportunities for the next generation' and 'We depend too much on science and not enough on faith', each of which have a difference of $35 \%$ between the highest and lowest responses, indicating an international divergence in public opinion. For the item 'Because of science and technology there will be more opportunities for the next generation', the US response of 89 represents the highest level of optimism about the future prospects of science, whilst the lowest response of 54 in India reveals greater ambivalence. For the item 'We depend too much on science and not enough on faith', the Indian response of 74 indicates a substantial level of religious or cultural concern about science, while the European response of 40 indicates a greater belief in the scientific world view. Similarly, the item 'Science makes our way of life change too fast' received a high response in the developing countries - South Africa (73) and India (75) - and a lower response in the developed countries - the EU (60) and the USA (46). The Indian study did not gauge attitudes to the statement 'It is not important for me to know about science in my daily life'; however, this item scored the lowest reservation in the other countries. This exclusion may have contributed to the elevated reservation index for India. Understanding the causes and implications of these findings falls into a broader research agenda, but these results do highlight that each country has a unique 'fingerprint' that defies easy answers and categorisation.

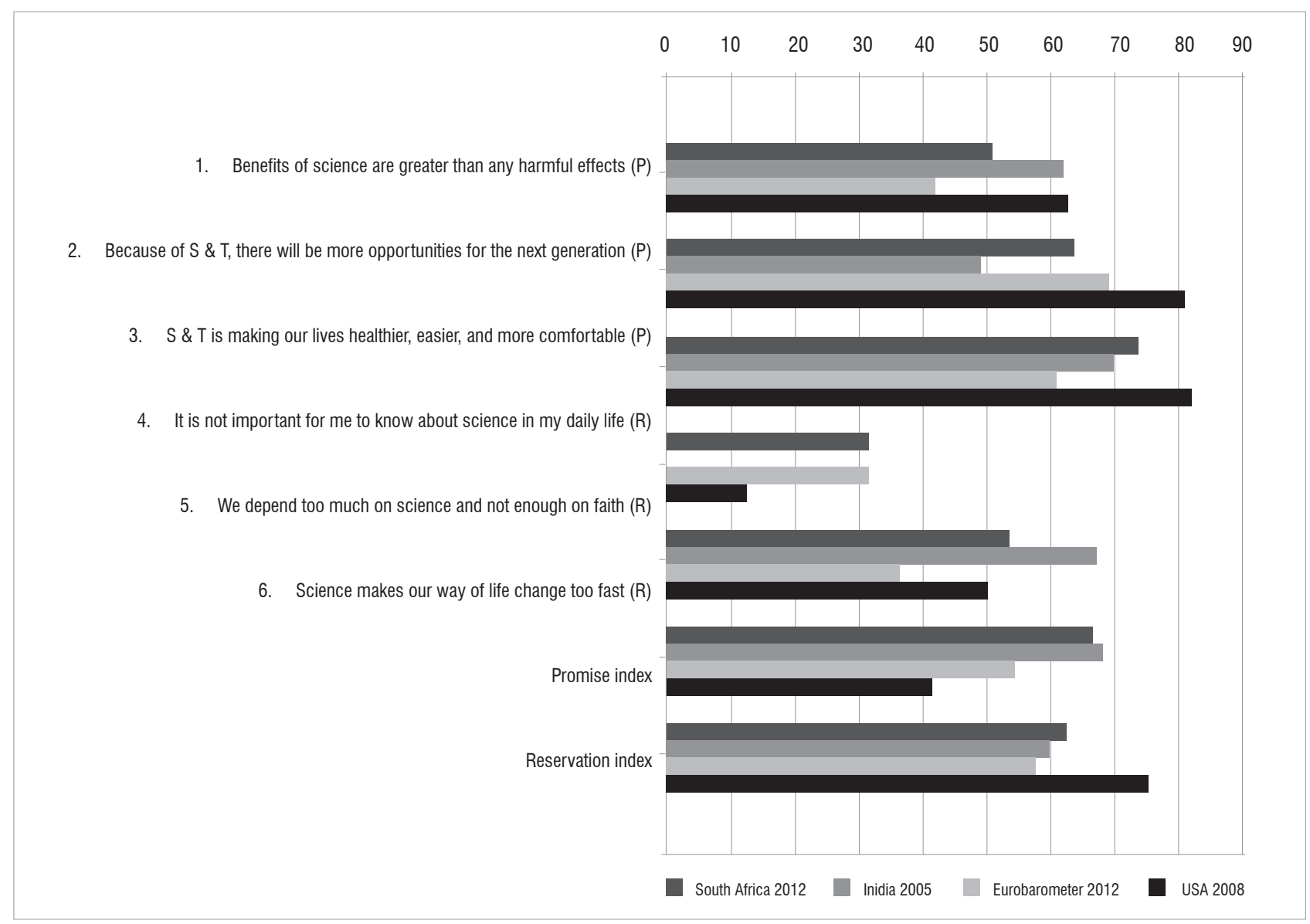

Source: South African Social Attitudes Survey ${ }^{24}$

$R$, reservation item; P, promise item

Figure 2: Comparison of performance on promise-reservation items among South Africa, Europe, India and the USA. 


\section{Attitudes by educational level, age and gender}

South African society is socially and economically highly stratified. To understand how this stratification affects attitudes towards science, we analysed the data according to educational level, age, gender and geographical location (Figures 3 and 4). The promise-reservation ratio decreased in South Africa from 1999 to 2010, and decreased for the disaggregated categories of gender, age and educational level (Figure 3). This decrease can be attributed to the decrease in the promise index and the increase in the reservation index from 1999 to 2010 (Figure 4).

Table 3: Promise-reservation ratio for South Africa (2010), India (2005), Europe (2010) and the USA (2008) by gender, age and educational leve

\begin{tabular}{|l|l|l|l|l|}
\hline \hline & $\begin{array}{l}\text { South } \\
\text { Africa } \\
(\mathbf{2 0 1 0 )}\end{array}$ & $\begin{array}{l}\text { Indiä } \\
(\mathbf{2 0 0 5 )}\end{array}$ & $\begin{array}{l}\text { Europe } \\
(\mathbf{2 0 1 0 )}\end{array}$ & $\begin{array}{l}\text { USA }^{\dagger} \\
(\mathbf{2 0 0 8})\end{array}$ \\
\hline \hline $\begin{array}{l}\text { Promise-reservation } \\
\text { ratio }\end{array}$ & 1.2 & 1.1 & 1.4 & 1.7 \\
\hline Gender & 1.2 & 1 & 1.3 & 1.7 \\
\hline Female & 1.2 & 1.1 & 1.5 & 1.8 \\
\hline Male & 1.3 & 1.1 & 1.6 & 1.5 \\
\hline Age ${ }^{\ddagger}$ & 1.2 & 1.1 & 1.5 & 1.8 \\
\hline Youth & 1.2 & 1.1 & 1.3 & 1.7 \\
\hline Adult & & & & \\
\hline Senior & 1.1 & 1 & & - \\
\hline Educational level & 1.2 & 1.1 & & 1.6 \\
\hline No schooling & & & & \\
\hline $\begin{array}{l}\text { Up to and including } \\
\text { Grade 12 }\end{array}$ & 1.1 & & \\
\hline
\end{tabular}

\# In calculating the disaggregated ratios, there was missing data for each of the variables, which affected the disaggregated scores.

† Disaggregated figures are only available for three items

₹ Age categories differ in all data sources. For comparability, the categories "youth", "adult and "senior" are used loosely for illustrative purposes.

In South Africa, the promise-reservation ratio was similar for male and female respondents. This finding contrasts with data from India, Europe and the USA, in which male respondents had a higher promise-reservation ratio than female respondents. The promise-reservation ratio among both genders decreased in South Africa from 1999 to 2010 as a result of decreased attitudes of promise and increased attitudes of reservations. Within this general similarity, there is gender difference in the level of both promise and reservation. In 1999, female individuals responded with higher promise and higher reservations to science compared with male individuals. This pattern changed in 2010, when male individuals responded with higher promise than did female individuals.

In South Africa, age had a significant effect on attitudes towards science. The promise index, in 1999 and in 2010, decreased consistently with age with the youngest age group (16-19) showing the highest levels of promise. Similarly, the younger age groups reported higher levels of reservation and the older age groups reported lower levels with the exception of the senior age group in 1999 and 2010. Because attitudes of both promise and reservation generally decreased with age, the overall promise-reservation ratio did not vary widely among adults, but was higher among the youth because of their higher levels of promise. Internationally, the effects of age on the promise-reservation index vary. In India, the figure was consistent across age groups (bearing in mind the omission of one item from the survey which may have skewed the reservation score). In Europe, the ratio decreased with age and in the USA it increased from teenagers to adults and then decreased again in the older age groups.

The promise-reservation ratio also increased with educational attainment. In both 1999 and 2010, attitudes of promise strengthened as educational attainment increased, although the group with no schooling were in both cases an exception, reporting higher levels of promise than those with a Grade 1-7 education. Conversely, attitudes of reservation in 1999 decreased in relation to educational attainment, again with the exception of the group with no schooling, which reported higher levels of reservation than those with a matric or tertiary education. Attitudes of reservation were more diverse in 2010 , characterised by smaller variation by education. However, once aggregated, these differing characteristics lead to a promise-reservation ratio that increased with educational attainment in both 1999 and 2010. This result is in line with similar findings from India and the USA.

\section{Conclusion}

During the three-decade history of survey research on mass public opinion about science and technology, robust and enduring international debate about the nature of the public-science interface has seen the discourse shift progressively from 'science literacy' to concerns over the 'public understanding of science' paradigm and more recently to a 'science and society' agenda. Alongside these conceptual developments, the increasing availability and integration of comparative data pertaining to public attitudes and knowledge about science has begun to facilitate new forms of methodological re-examination and testing, including richer contextual and cross-cultural analysis. Against this backdrop, the review of extant research on the public's relationship with science in South Africa by Reddy et al. ${ }^{2}$ drew attention to a knowledge gap that exists as a consequence of a paucity of data to adequately describe this relationship. As an initial step in addressing this situation, a 'public relationship with science' module was developed for the 2010 SASAS, producing one of only a few nationally representative and internationally comparable data sources on attitudes towards science, science knowledge, and science communication in the country. These data, together with the analysis presented in this paper, are seen as the foundation for a broader, more ambitious programme of social scientific work aimed at imparting a more nuanced, culturally relevant and empirically reliable understanding of the relationship between science and society in our country, and how it evolves over time.

Our overview of the South African public's attitudes towards science portrays a complex and shifting balance between attitudes of promise and reservation. The majority of South Africans believe that science and technology makes their lives easier, healthier, and more comfortable; makes their work more interesting; and provides more opportunities for the future. Conversely, a significant majority of the population expresses concern that science is making their way of life change too fast, and that we depend too much on science and not enough on faith. Between 1999 and 2010, there was a slight overall weakening in attitudes of promise and an overall strengthening in attitudes of reservation, leading to an overall decrease in the promise-reservation ratio.

From an international perspective, South Africa has a unique 'fingerprint' of public attitudes towards science. For instance, whereas male respondents exhibited a higher promise-reservation ratio than female respondents in India, Europe and the USA alike, there is little evidence of gender-based differences in South Africa. Furthermore, there is a notably strong age gradient in science attitudes in the country: measures of both promise and reservation tend to decrease with age. This pattern is distinct from that observed in other contexts. In India, age has little effect on attitudes, in Europe the promise-reservation ratio decreases with age, and in the USA it is higher amongst adults than teenagers or older age groups. This finding raises interesting questions about generational and period effects in science attitudes in South Africa, and whether the post-apartheid generation, with increased educational levels, is characteristically different. The promise-reservation ratio in South Africa also increases with educational attainment - in this case revealing a similar pattern to India and the USA.

Our initial findings highlight some directions for further research that can meet the growing academic and policy interest in the interface between the institutions of science and the public. Moving beyond a simple bivariate analysis, regression analysis could examine specific publics of 


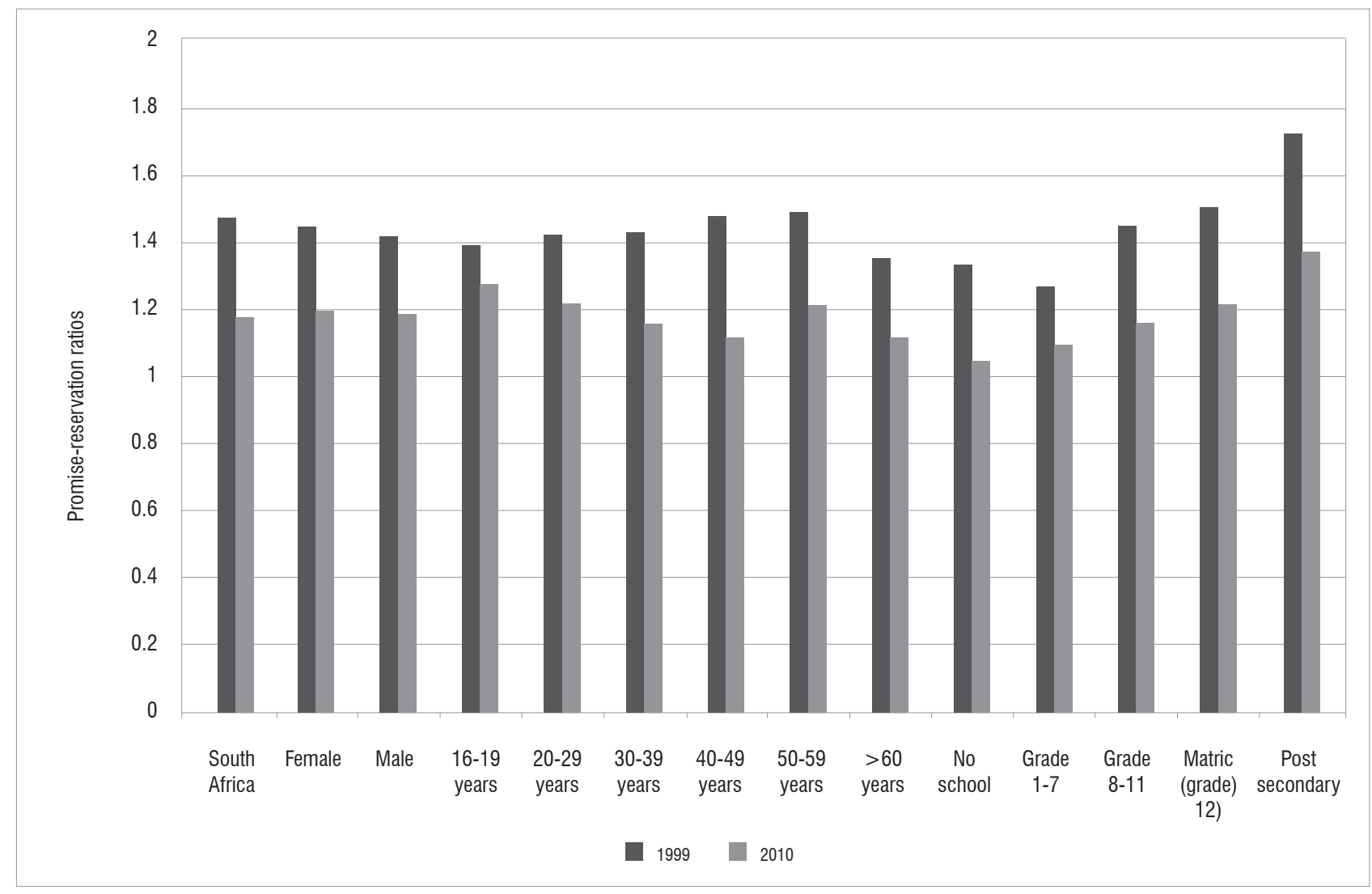

Figure 3: Promise-reservation ratio by gender, age and educational level for 1999 and 2010.

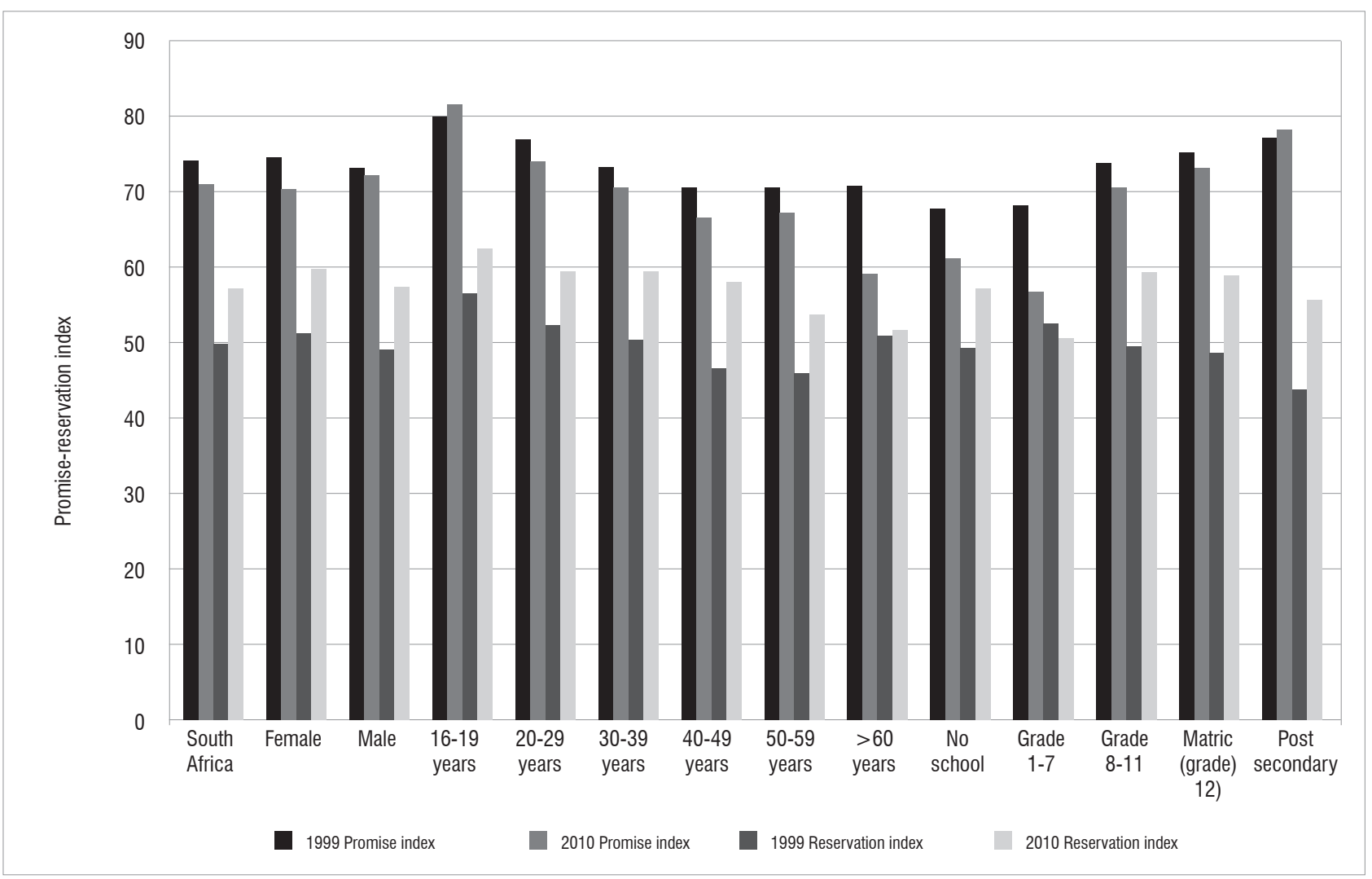

Figure 4: Promise and reservation indices by gender, age and educational level for 1999 and 2010. 
interest (e.g. rural women and the Black urban middle class) that will help us understand the 'topography' of the public relationship towards science in a stratified society. Multivariate analyses could more clearly separate the independent effects of education, gender and other variables. Further analysis incorporating data describing science knowledge and science communication, and also examining bidirectional relationships between the public and the institutions of science, will allow us to move beyond 'public attitudes towards science' towards the 'public relationship with science', in which knowledge, attitudes, and science communication form complex relationships with each other and in their social and demographic contexts.

\section{Authors' contributions}

V.R. was the principal author and project manager. M.G. was involved in the conceptualisation of the study and the writing of the paper. A.J. was involved in the data construction and analysis and the writing of the paper. B.R. provided data support and analysis.

\section{References}

1. Bauer M, Allum N, Miller S. What can we learn from 25 years of PUS survey research? Liberating and expanding the agenda. Public Underst Sci. 2007;16(1):79-95. http://dx.doi.org/10.1177/0963662506071287

2. Reddy V, Juan A, Gastrow M, Bantwini B. Science and the publics: A review of public understanding of science studies. Pretoria: South African Agency for Science and Technology Advancement; 2009.

3. Allum N, Sturgis P, Tabourazi D, Brunton-Smith I. Science knowledge and attitudes across cultures: A meta-analysis. Public Underst Sci. 2008;17(1):35-54. http://dx.doi.org/10.1177/0963662506070159

4. Gregory J, Lock S. Evolution of "Public understanding of science": Public engagement as a tool of science policy in the UK. Socio Comp. 2008;2(4):1252-1265. http://dx.doi.org/10.1111/j.17519020.2008.00137.x

5. Miller JD. The American people and science policy. New York: Pergamon Press; 1983

6. Department of Science and Technology (DST). Innovation towards a knowledge-based economy: Ten-year plan for South Africa (2008-2018). Pretoria: DST; 2007.

7. Miller JD. The public understanding of science in Europe and the United States [document on the Internet]. c2007 [cited 2008 Nov 28]. Available from: http://shop.lawrencemg.com/s036-p-263.html

8. Felt $U$, Fochler $M$. The bottom-up meanings of the concept of public participation in science and technology. Sci Public Pol. 2008;35(7):489499. http://dx.doi.org/10.3152/030234208X329086

9. Stocklmayer S, Gilbert JK. New experiences and old knowledge: Towards a model for the personal awareness of science and technology. Int J Sci Educ. 2002;24(8):835-858. http://dx.doi.org/10.1080/09500690210126775

10. Elam M, Bertilsson M. Consuming, engaging and confronting science: The emerging dimensions of scientific citizenship. Eur J Soc Theor. 2003:6:233251. http://dx.doi.org/10.1177/1368431003006002005

11. Miller JD. The measurement of civil scientific literacy. Public Underst Sci. 1998;7:203-223. http://dx.doi.org/10.1088/0963-6625/7/3/001

12. Durant J. Participatory technology assessment and the democratic mode of the public understanding of science. Sci Pub Pol. 1999;26(5):313-319. http://dx.doi.org/10.3152/147154399781782329

13. Raza G, Singh S, Dutt B. Public, science, and cultural distance. Sci Commun. 2002;23(3):293-309. http://dx.doi.org/10.1177/107554700202300305

14. Bauer M, Petkova K, Boyadjieva P. Public knowledge of and attitudes to science: Alternative measures that may end the "science war". Sci Tech Hum Val. 2000;25(1):30-51. http://dx.doi.org/10.1177/016224390002500102

15. Burns T, O'Connor D, Stockmayer S. Science communication: A conceptual definition. Public Underst Sci. 2003;12:183-202. http://dx.doi. org/10.1177/09636625030122004
16. National Science Foundation. Science and technology: Public attitudes and understanding. Science and engineering indicators 2008. Arlington, WA: National Science Board; 2008

17. European Commission. Eurobarometer 73.1 [database on the Internet]. c2012 [cited 2012 July 01]. Available from: http://info1.gesis.org/ dbksearch19/download.asp?db $=$ D\&id $=37220$

18. Shukla R. India science report. New Delhi: National Council of Applied Economic Research; 2005.

19. Pouris A. Understanding and appreciation of science by the public in South Africa. S Afr J Sci. 1991;87:358-359.

20. Pouris A. Understanding and appreciation of science among South African teenagers. S Afr J Sci. 1993;89(2):68-69.

21. Pouris A. Interests, public attitudes and sources of scientific information in South Africa [document on the Internet]. c2001 [cited 2008 Nov 28] Available from: www.visits.web.cern.ch/visits/pcst2001/proc/Pouris.doc

22. Pouris A. Assessing public support for biotechnology in South Africa. S Afr J Sci. 2003;99:513-516.

23. Laugksch RC. Development of a test for scientific literacy [thesis]. Cape Town: University of Cape Town; 1996.

24. Human Sciences Research Council. South African Social Attitudes Survey [database on the Internet]. c2011 [cited 2012 July 8]. Available from: http:// info1.gesis.org/dbksearch19/Docs.asp?no $=4850$

25. Mick D, Fournier S. Paradoxes of technology: Consumer cognizance, emotions, and coping strategies. J Consum Res. 1998;25(2):123-143. http://dx.doi.org/10.1086/209531

26. Bawden D, Robinson L. The dark side of information: Overload anxiety and other paradoxes and pathologies. J Info Sci. 2009;35(2):180-191. http:// dx.doi.org/10.1177/0165551508095781

27. Anthony M, Clarke M, Anderson S. Technophobia and personality subtypes in a sample of South African university students. Comput Hum Behav. 2000;16(1):31-44. http://dx.doi.org/10.1016/S0747-5632(99)00050-3

28. Koselleck R. Critique and crises: Enlightenment and the pathogenesis of modern society. Boston: MIT Press; 1998.

29. World Bank. World development indicators database [homepage on the Internet]. No date [cited 2011 Feb 06]. Available from: www.data.worldbank. org/data-catalog/world-development-indicators.

\section{Appendix 1: List of promise-reservation items}

\section{Promise items}

1. Science and technology is making our lives healthier, easier, and more comfortable

2. Because of science and technology there will be more opportunities for the next generation

3. Benefits of science are greater than any harmful effects

4. Scientists and engineers have a prestigious occupation

\section{Reservation items}

1. Science makes our way of life change too fast

2. We depend too much on science and not enough on faith

3. It is not important for me to know about science in my daily life 